\title{
NUCLEOLAR ORGANISER AS A HYPERACTIVE LOCUS FOR RNA SYNTHESIS
}

\author{
H. K. JAIN, R. N. RAUT and S. K. NERWAL \\ Division of Genetics, Indian Agricultural Research Institute, New Delhi
}

Received 1.iii.68

\section{INTRODUGTION}

Although our present understanding of the transfer of genetic information from the nucleus to the cytoplasm is based largely on micro-organisms, whose nuclei do not show the same kind of nucleolar and chromosomal organisation as those in the higher organisms, there have been suggestions that the nucleolus is involved in such a transfer in the latter group. Thus, Caspersson (1950) and Brachet (1957) have maintained that the nucleolar RNA, synthesised by chromatin material, plays a role in cytoplasmic protein synthesis. In more recent years, this question has been discussed by a number of authors including Sirlin (1962). In order to study the nature of nucleolar RNA, it is necessary to take into consideration the mode of formation of the nucleolus. Some evidence already available in this regard, following the pioneering work of Heitz (1931) and McClintock (1934), suggests that the nucleolar material is formed through the synthetic activity of a specific locus in the chromosomal complement (Lin, 1955; Crosby, 1957; La Cour, 1966). In the course of the present study, an understanding of nucleolar synthesis has been sought by observing the incorporation of tritiated uridine, a precursor of RNA, into the root tip cells of three different varieties of hyacinth showing variation in their chromosome number.

\section{Material and methods}

The first of the three varieties of Hyacinthus orientalis was Early Roman with a diploid number of 16 chromosomes; the second, Rosalie, a trisomic having an extra homologue of the nucleolus organising chromosome; and the third, Anne Marie, a triploid with 24 chromosomes (Darlington et al., 1951). Bulbs of each of these varieties were grown for various durations ranging from 1 to 4 hours in equal volumes of distilled water containing tritium labelled uridine (specific activity $2 \cdot 2 \mathrm{G} / \mathrm{m} \mathrm{Mol}$.). After fixation in an acetic acid-ethanol mixture $(1: 3)$ the root tips were softened in 5 per cent. pectinase and squashed in 45 per cent. acetic acid. Immediately after making the preparations, the cover glass was removed by the dry ice method and the slides stored in 95 per cent. alcohol. The unincorporated tritium label was removed from the preparations by extracting the slides with 2 per cent. perchloric acid at a temperature of $4^{\circ} \mathrm{C}$. for 40 minutes. The autoradiographs were prepared with the standard stripping film (Kodak AR 10) technique and stained with a mixture of methyl green and pyronin (see Darlington and La Cour, 1962). The incorporation of label was studied in the interphase cells. The cells in division were not scored. 


\section{Observations}

A quantitative comparison of the incorporation of label in cells of the different varieties presented some difficulty and could be attempted with some of the treatments only, as will be seen from the following observations.

First treatment: The labelled solution at a concentration of $5 \mu \mathrm{c} / \mathrm{ml}$. was used and the roots were kept in it for 1 and $1 \frac{1}{2}$ hours. The autoradiographs were prepared after exposing the film for a 2-month period. The treatment resulted in significant incorporation of the label. However, the silver grains in most of the cells were concentrated over the nucleoli and were packed so densely that no counting was possible (fig. 1). The nucleoli could be readily located by their differential stainability and characteristic form (fig. 2). It was clear that when the root tips were kept in the precursor solution for a relatively short period of $1-1 \frac{1}{2}$ hours, the label was incorporated mostly in the nucleolus. The number of nucleoli was found to vary from 1 to 2 in cells of the diploid strain, while it varied from 1 to 3 in cells of the trisomic and triploid strains. It is not uncommon for the nucleoli in a nucleus to fuse together and this can account for variation in their number in different cells.

TABLE 1

Inter and Intra-varietal variation in cell size

$\begin{array}{lc}\quad \text { Variety } & \begin{array}{c}\text { Range in cell size } \\ \left.\text { (area in } \mu^{2}\right)\end{array} \\ \text { Early Roman } & 270 \cdot 00-576 \cdot 00 \\ \text { Rosalie } & 302 \cdot 40-604 \cdot 80 \\ \text { Anne Marie } & 345 \cdot 60-745 \cdot 20\end{array}$

Second treatment: The root tips were kept in the radioactive solution of a concentration of $3 \mu \mathrm{c} / \mathrm{ml}$. for a period of four hours. They were fixed immediately afterwards as in the earlier treatment. The autoradiographs were processed after an exposure period of 30 days. The cells showed good incorporation of the label and the grains were found to be distributed over the nucleus as well as the cytoplasm. This non-localised distribution of the label was in sharp contrast to the condition observed in the first treatment. Counting of grains was found possible in this case and cells were scored in five different slides from each variety.

In selecting the cells for grain count, two criteria were employed. First, those cells which were relatively unstained were not taken into consideration. For some reason, a number of cells appeared to be damaged and to have lost much of their nuclear and cytoplasmic materials during the processing of the slides. Only those cells which appeared intact and showed good stainability were scored. Secondly, as expected, considerable variation was observed in the size of different cells from the same root tip. Also, there was considerable intervarietal variation in cell size. Ignoring the few cells showing extreme variation (these were exceptionally small or large), the cells of the different varieties showed the following range in size.

It is clear that cells of the triploid strain tend to be larger than those of the trisomic and diploid; and the cells of the trisomic variety larger than those of the diploid. Twenty cells falling within the size range specified above were scored for grains in each slide for each of the three varieties. Within the characteristic range of a variety, the cells were scored at random. 
The background grain formation was also scored. This was done by marking out under the microscope small areas in the vicinity of the scored cells. Thus, for each of the cells, a blank area of approximately the same size was scored. For the purpose of comparison and statistical analysis, the background count was deducted from the number of grains scored in the corresponding cells, and the net number of grains per cell obtained. The following table (table 2) illustrates the way in which scoring of different cells was done in one of the varieties.

TABLE 2

Scoring of silver grains in variety Roman

$\begin{array}{cccc}\begin{array}{c}\text { Slide 1, } \\ \text { cell no. }\end{array} & \begin{array}{c}\text { No. of } \\ \text { grains }\end{array} & \begin{array}{c}\text { No. of back- } \\ \text { ground grains }\end{array} & \begin{array}{c}\text { Net no. } \\ \text { of grains }\end{array} \\ 1 & 30 & 5 & 25 \\ 2 & 33 & 4 & 29 \\ 3 & 29 & 3 & 26 \\ 4 & 27 & 4 & 23 \\ 5 & 35 & 3 & 32 \\ 6 & 31 & 5 & 26 \\ 7 & 37 & 4 & 33 \\ 8 & 35 & 3 & 32 \\ 9 & 26 & 4 & 22 \\ 10 & 29 & 5 & 24 \\ 11 & 28 & 3 & 25 \\ 12 & 25 & 2 & 23 \\ 13 & 29 & 3 & 26 \\ 14 & 31 & 5 & 26 \\ 15 & 34 & 4 & 30 \\ 16 & 30 & 3 & 27 \\ 17 & 41 & 4 & 37 \\ 18 & 38 & 3 & 35 \\ 19 & 36 & 2 & 34 \\ 20 & 33 & 3 & 30 \\ & & & \\ \text { Mean } & 31 \cdot 85 & 3 \cdot 60 & 28 \cdot 25\end{array}$

Table 3 summarises observations on all the three strains. In this the mean number of net grains per cell for each of the five slides is given, together with the standard errors of these mean values.

The observations in table 3 are based on scoring of cells belonging to different size ranges in the three varieties. A second group of cells was also scored; these cells were selected so as to conform to virtually the same size range in each of the three varieties. These observations are summarised in table 4.

The data presented in table 3 and 4 have been analysed statistically. The analysis of variance is given in table 5 ( $a$ and $b$ ) and table 6 ( $a$ and $b$ ).

It will be seen from the above analysis that the different root tips of a variety show significant differences in the incorporation of the label. Notwithstanding this variation, it is observed that the intervarietal differences in the incorporation of label are highly significant.

The extent of these inter-varietal differences can be seen by pooling observations on all five slides (i.e. five root tips) of a variety and by computing the mean number of grains per cell from the pooled observations. These mean values for the different varieties are given in table 7 . 

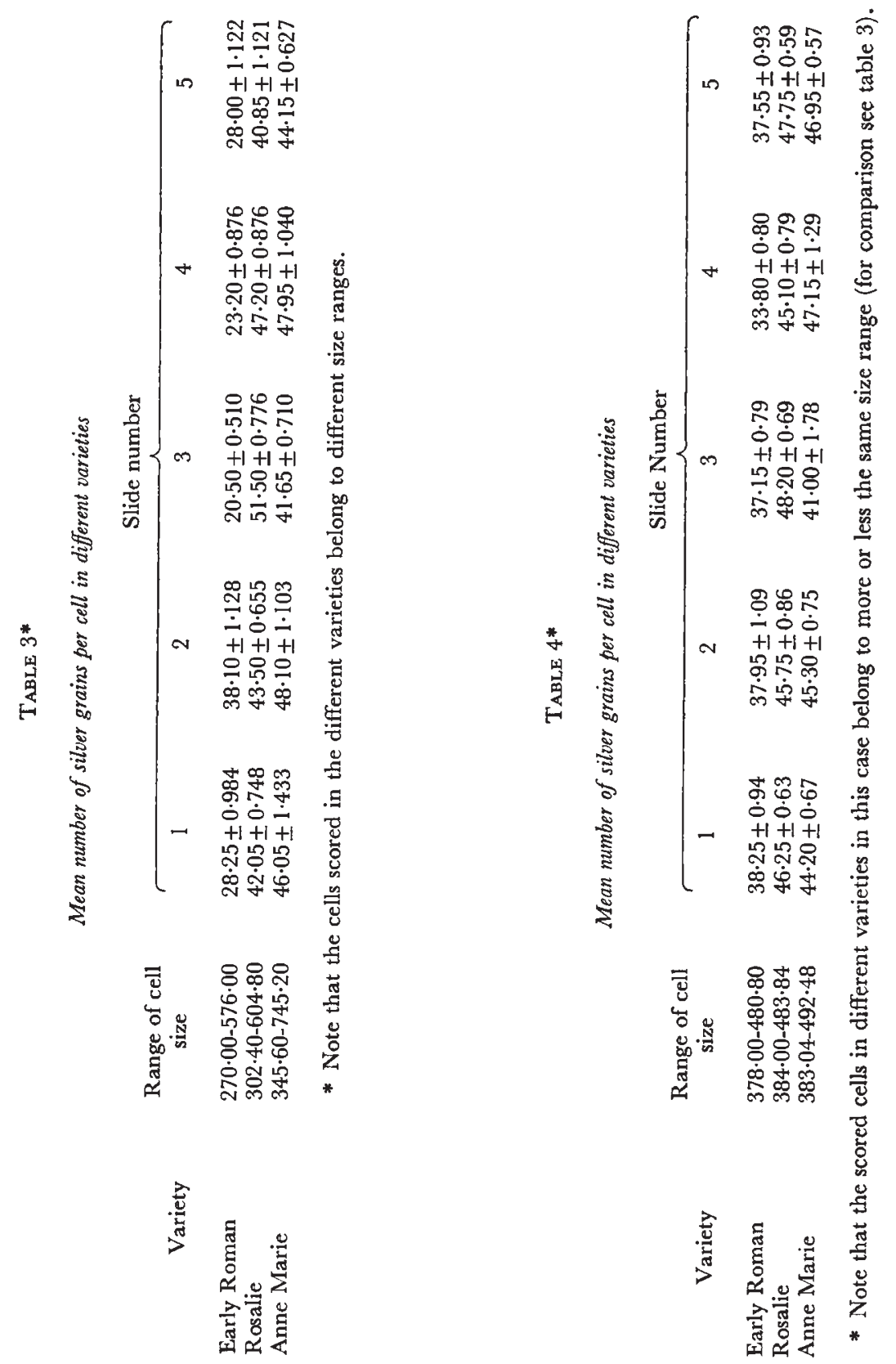
TABLE 5

Analysis of variance of the data in table 3

(a): Between varieties

Due to D.F. $\quad$ M.S. $\overbrace{\text { Calculated }}^{\text {F value }} \overbrace{\text { Tabulated (5\%) }}$

Varieties

$2 \quad 521 \cdot 952$

$23 \cdot 795$

$21 \cdot 935$

$3 \cdot 88 * *$

(b): Within varieties

\begin{tabular}{|c|c|c|c|c|c|}
\hline & & & & $\mathbf{F}$ & lue \\
\hline Varieties & Due to & D.F. & M.S. & Calculated & $\begin{array}{c}\text { Tabulated } \\
(5 \%)\end{array}$ \\
\hline Early Roman & $\begin{array}{l}\text { Slides } \\
\text { Error }\end{array}$ & $\begin{array}{r}4 \\
94\end{array}$ & $\begin{array}{r}903 \cdot 010 \\
18 \cdot 229\end{array}$ & $49 \cdot 537$ & $2 \cdot 46 * *$ \\
\hline Rosalie & $\begin{array}{l}\text { Slides } \\
\text { Error }\end{array}$ & $\begin{array}{r}4 \\
95\end{array}$ & $\begin{array}{r}267 \cdot 815 \\
10 \cdot 386\end{array}$ & $25 \cdot 786$ & $2 \cdot 46 * *$ \\
\hline Anne Marie & $\begin{array}{l}\text { Slides } \\
\text { Error }\end{array}$ & $\begin{array}{r}4 \\
95\end{array}$ & $\begin{array}{r}136 \cdot 960 \\
21 \cdot 117\end{array}$ & $6 \cdot 485$ & $2 \cdot 46 * *$ \\
\hline
\end{tabular}

TABLE 6

Analysis of variance of the data in table 4

(a): Between varieties

Due to

Varieties

Error

M.S.

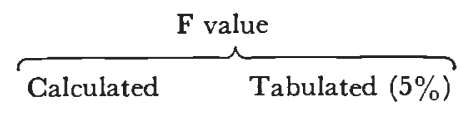

$2 \quad 161 \cdot 005$

$41 \cdot 357$

$3 \cdot 88 * *$

$12 \quad 3.893$

(b): Within varieties

Varieties

Due to

D.F.

M.S.

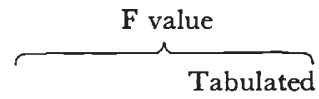

Early Roman

Slides

$4 \quad 65 \cdot 060$

95

$16 \cdot 898$

$3 \cdot 850$

(5\%)

Rosalie

Slides

$4 \quad 34.885$

Error

95

$10 \cdot 444$

$3 \cdot 340$

$2 \cdot 46$ *

Anne Marie

Slides

4

$133 \cdot 615$

$5 \cdot 349$

$2 \cdot 46 * *$ 
It is clear from table 7 that the trisomic and the triploid varieties show an identical level of grain formation, and that this level is nearly one and a half times greater than that in the diploid variety, when cells in the different varieties are scored irrespective of variation in their size. However, when cells conforming to the same size range are scored in the different varieties, the difference is not so large. The trisomic and the triploid cells again show more or less the same number of grains per cell, and this number is nearly 27 per cent. more than that in the diploid variety (see figs. 3-5).

Third treatment: The treatment involved keeping the root tips in the radioactive solution $(2 \mu \mathrm{c} / \mathrm{ml}$.) for a duration of four hours. A distinguishing feature of this treatment was that the root tips were not fixed immediately after their removal from the labelled solution. They were washed and kept in distilled water for six hours prior to their fixation. The autoradiographs were processed after an exposure period of 80 days. The cells following this treatment showed a non-localised distribution of the grains. However, the

TABLE 7

Mean number of grains per cell (pooled observations from different root tips)

$\begin{array}{cccc}\begin{array}{c}\text { Cell } \\ \text { size } \\ \text { range }\end{array} & \overbrace{\text { Early Roman }} \text { Mean no. of grains per cell } \\ & \text { Rosalie } & \text { Anne Marie } \\ * 1 & 27 \cdot 61 \pm 0.730 & 46 \cdot 02 \pm 0.453 & 45 \cdot 64 \pm 0.337 \\ * 2 & 36.94 \pm 0.432 & 46 \cdot 61 \pm 0.336 & 46.92 \pm 0.529\end{array}$

*1. Cells belong to different size ranges in the three varieties.

*2. Cells belong to virtually the same size ranges in the three varieties.

grain formation was so intense that no counting was possible. These autoradiographs have been particularly useful for two reasons. First, the incorporation of label in the cells was so great that the background grains appeared quite negligible. Secondly, although the grains could not be counted, it was quite clear that the incorporation was much less in the diploid cells compared to the trisomic and triploid. A large number of grains in cells of the diploid strain could be resolved from one another, unlike the other varieties in which widespread colescence made this difficult (figs. 6 6). It could be concluded that grain formation in the trisomic and the triploid varieties was comparable and considerably greater than in the diploid strain.

\section{Discussion}

A number of studies have been made to determine the sites of RNA synthesis in the cell. The results from several of these studies using the autoradiographic technique were summarised by Woods and Taylor (1959). It was observed in the course of most of these experiments that the labelled precursors of RNA are incorporated mostly in the nucleus, when the cells are exposed to them for a short duration. Following longer duration, the label appeared both in nucleus and the cytoplasm. These findings led to the conclusion that a large part of the cytoplasmic RNA is of nuclear origin. Woods and Taylor (1959) made the further observation that in the actively 
dividing root tip cells of Vicia faba the labelled RNA was not uniformly distributed over the chromosomal complement but was confined mostly to the nucleolus. The rapid incorporation of the labelled precursor in the nucleolus was earlier observed by McMaster and Taylor (1958) in the course of their studies on the giant salivary gland cells of Drosophila. The autoradiographs prepared by these authors showed incorporation of $\mathrm{P}^{32}$ first in the nucleolus and later in the other nuclear and cytoplasmic parts of the cell.

The present observations on incorporation of uridine in the root tip cells support the concept that a major part of the cytoplasmic RNA is of nuclear origin. It has been found that when uridine was fed to the root tips for a short time, most of the label was incorporated in the nucleolus. Only when the feeding period was extended over several hours, the label began to appear in the cytoplasm. In many of the cells following these extended treatments, it can be seen that with the appearance of label in the cytoplasm, the nucleolus no longer shows a heavy concentration of the grains, as it does in cells exposed to the precursor for shorter durations ( $c f$. figs. 1 and 7). These observations correspond to the findings of Woods and Taylor (1959) in the case of Vicia faba cells, and suggest that some of the RNA from the nucleolus migrates to the cytoplasm.

The differential incorporation of the label in the root tip cells of the diploid and trisomic strains is of particular interest in relation to the role of nucleolar organiser in RNA synthesis. The significantly greater incorporation in the trisomic compared to the diploid cells clearly points to an important role of the organising chromosome in this synthesis. This role is further supported by the finding that the triploid cells, having a whole set of extra chromosomes, show a degree of incorporation which is not greater than that of the trisomic cells, in which only the nucleolar chromosome has an extra homologue. These observations clearly suggest that the nucleolar RNA may be synthesised largely through the synthetic activity of the nucleolar chromosome rather than the nuclear complement as a whole, as suggested by Woods and Taylor (1959). It is also possible that only the organising locus in this chromosome contributes to the synthesis of nucelolar RNA; this however is not proved by the present observations. In either case, it follows that the nucleolar RNA is more likely to be associated with fractions like the ribosomal and transfer RNA rather than the messenger RNA, which is expected to be contributed by a much larger number of gene loci scattered in the nucleus as a whole.

The finding that nucleolar RNA is synthesised by the chromosome having the organiser rather than the nuclear complement as a whole was first made by Lin (1955) many years ago. The evidence described by Lin, following absorption micro-spectrophotometric determination of RNA content in the nucleolus of maize strains differing in their chromosomal constitution, was both critical and convincing. Notwithstanding this, the role of the nucleolar chromosome has continued to be debated (see reviews by Vincent, 1955; Sirlin, 1962, 1963; Busch et al., 1963). In particular, Sirlin et al. (1963) and Birnstiel et al. (1965) have continued to stress that the synthesis of nucleolar RNA begins in the nucleolus itself and that it is independent of the organiser. There has, therefore, been a need to reinforce Lin's conclusions.

The autoradiographic technique used in the course of the present study has further shown that the content of RNA in the cell as a whole is correlated with the number of nucleolar chromosomes. Lin established the correlation 
between the organising chromosomes and the RNA content of the nucleolus. The present study thus indicates that a greater part of the RNA in the interphase cell is of nucleolar origin. The autoradiographic technique also offers other advantages, particularly in analysing the turnover of RNA.

The conclusion on the role of the nucleolar chromosome finds support from the molecular hybridisation experiments of Spiegelman and his collaborators (Ritossa et al., 1966, Ritossa and Spiegelman, 1965) who found that there is good complementarity between the bases of ribosomal RNA and those of the DNA of the nucleolar organising locus. Thus, they identified the nucleolar organiser as having the DNA template responsible for the synthesis of ribosomal RNA. Further support for the conclusion that the nucleolar organiser is active in the synthesis of ribosomal RNA is provided by the observations of Brown and Gurdon (1964) on an anucleolar mutant of Xenopus. These authors found that the RNA synthesis in the mutant lacking the nucleolar organiser was greatly reduced; and the ribosomal fraction was the one most affected.

\section{Summary}

1. Incorporation of tritium labelled uridine has been studied in three varieties of hyacinth showing variation in their chromosome number.

2. The incorporation of the label is comparable in the triploid and the trisomic strains, the latter having an extra homologue of the nucleolar organising chromosome.

3. Root tip cells of both these strains show significantly greater uptake of the RNA precursor compared to cells of the diploid variety.

4. It is concluded that the chromosome having the nucleolar organiser is active in the synthesis of the bulk of RNA in the root tip cells.

\section{REFERENCES}

BIRNSTIEL, M. L., SIRLIN, J. L., AND JACoB, J. 1965. The nucleolus: a site of transfer ribonucleic acid synthesis. Biochem. 7., 94, 10-11.

BRAchet, J. 1957. Biochemical Cytology. New York, Academic Press.

BROWN, D. D., AND GURDON, J. B. 1964. Absence of ribosomal RNA synthesis in the anucleolate mutant of Xenopus laevis. Proc. Nat. Acad. Sci. (Wash.), 51, 139-146.

BUSCH, H., BYVOet, P., AND SMETANA, K. 1963. The nucleolus of the cancer cell: A review Cancer Res., 23, 313-339.

CASPERsSon, T. 1950. Cell growth and cell function, ed. Norton, W. W. New York.

CrosBy, A. R. 1957. Nucleolar activity of lagging chromosomes in wheat. Amer. J. Bot., 44, 813-822.

DARLINGTON, C. D., HAIR, J. B., AND HURCOMBE, R. 1951. The history of garden hyacinths. Heredity, 5, 233-252.

DARLington, C. D., AND LA COUR, L. F. 1962. The handling of chromosomes. London, George Allen and Unwin Ltd.

Heitz, E. 1931. Die Ursache der gesetzmabign Zahl, Lage Form Und Grobe pflanzlicher Nukleolen. Planta (Berl.), 12, 775-844.

LIN, M. 1955. Chromosomal control of nuclear composition in maize. Chromosoma (Berl.), $7,340-370$

LA CoUR, L. F. 1966. The internal structure of nucleoli. Chromosomes Today, Vol. 1, pp. 150, ed. Darlington and Lewis, London, Oliver and Boyd.

MCMASTER, R., AND TAYLOR, J. H. 1958. Evidence for two metabolically distinct types of ribonucleic acid in chromatin and nucleoli. F. Biophys. Biochem. Cytol., 4, 5-11.

RITOSSA, F. M., AND SPIEgELMAN, s. 1965. Localisation of DNA complementary to ribosomal RNA in the nucleolus organiser region of Drosophila melanogastor. Proc. Nat. Acad. Sci. (Wash.), 53, 737-745. 


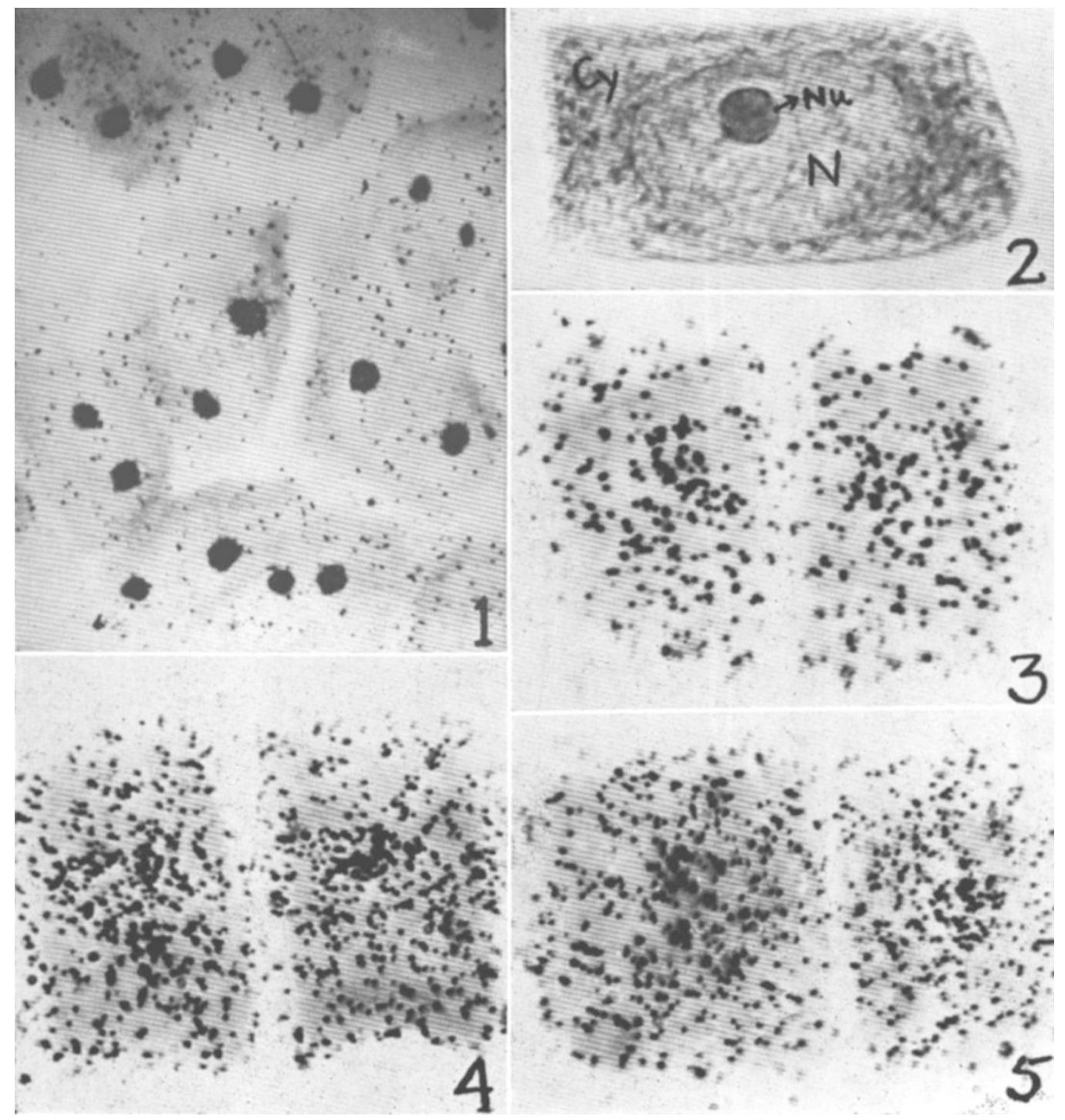

FIG. 1.-Autoradiographs from root tip cells following incorporation of the tritium label for a short duration. It will be seen that most of the grains are concentrated over the nucleoli (treatment 1 ). $\times 800$.

FIG. 2.-Photomicrograph of an interphase cell from a root tip of the diploid variety. The nucleolus $(\mathrm{Nu})$, the nucleus $(\mathrm{N})$ and the cytoplasm (Cy) can be clearly seen. $\times 2000$.

Figs. 3-5.-Autoradiographs from root tip cells of the diploid, trisomic and triploid varieties respectively. The grains in each case are found to be scattered over the cell as a whole (treatment 2). $\times 1800$ all. 


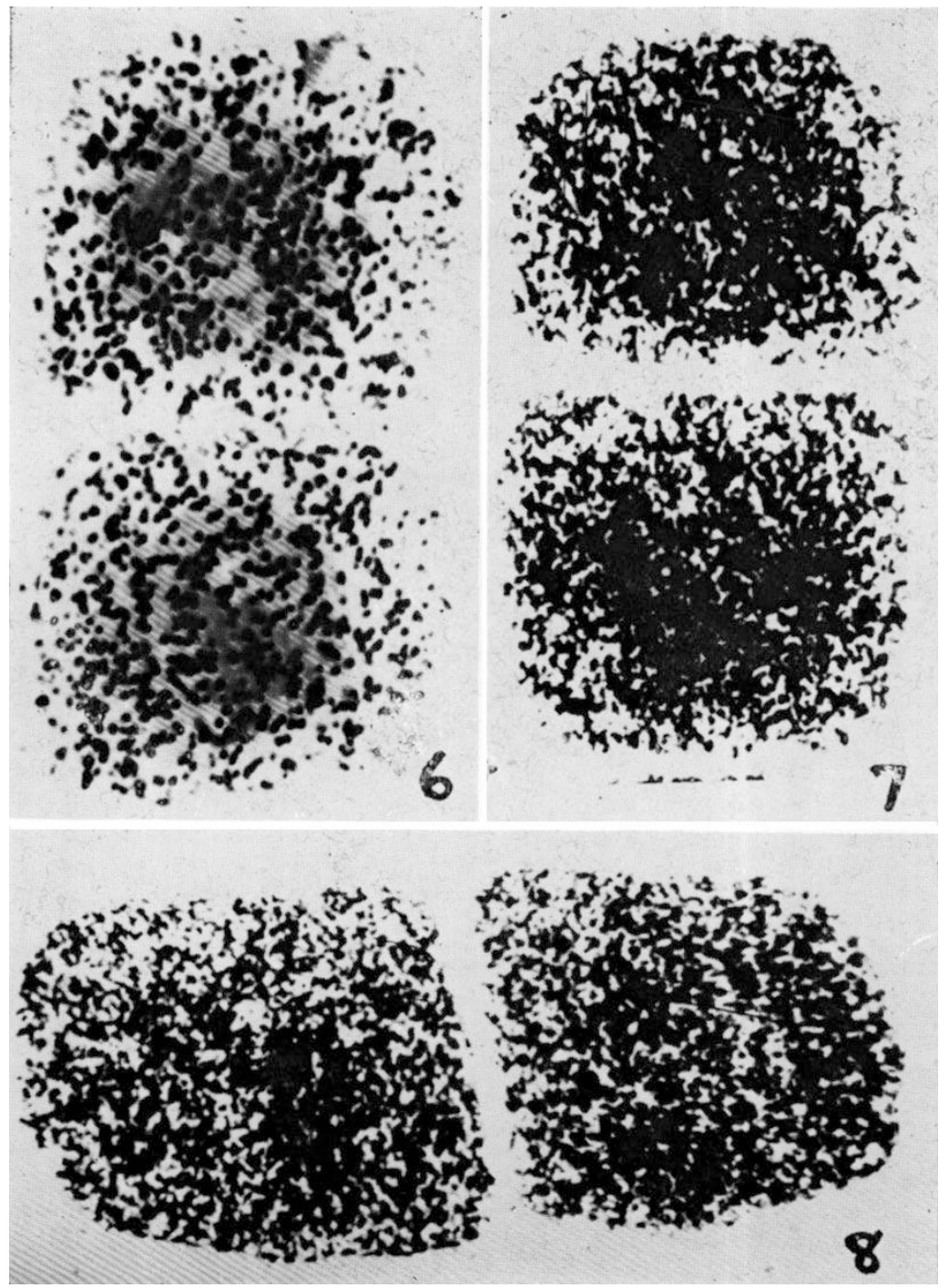

Figs, 6-8.-Heavier concentration of grains in the autoradiographs of the three varieties following treatment no. 3. fig. 6 shows cells of the diploid variety. It will be seen that many of the grains can be resolved from one another. Figs. 7 and 8 show autoradiographs of the trisomic and triploid varieties respectively. In these, resolution of individual grains does not appear to be possible. $\times 2200$ all. 
RITOSSA, F. M., ATWOOD, D. L., LINDsKy, D. L., AND SPIEgELMAN, s. 1966. On the chromosomal distribution of DNA complementary to ribosomal and soluble RNA. In: The Nucleolus, its structure and function. Nat. Cancer Inst. Monogr., 23, 449-472.

sirlin, J. L. 1962. The Nucleolus. Progr. Biophys. Chem. 12, 27-66.

SIRLIN, J. L. 1963. The intracellular transfer of genetic information. Int. Rev. Cytol. (Ed. Bourne, G. H. and Danielli, J. E.), 15, 35-96.

SIRLIN, J. L., TANDLER, C. J., AND JACOB, J. 1963. The relationship between the nucleolus organiser and nucleolar RNA. Expt. Cell Res. 31, 611-615.

vincent, w. S. 1955. Structure and chemistry of nucleoli. Int. Rev. Cytol. 4, 269-298.

wOODS, P.s., AND TAYLOR, J. H. 1959. Studies of Ribonucleic acid Metabolism with Tritiumlabelled cytidine. Lab. Investigation, 8, 309-318. 